\title{
Hua Ming Mode----A Case Study of Tianjin Small Town Construction
}

\author{
Ma Jian, He Yongjian \\ No. 89 Huangpu S Rd, Hexi, Tianjin, China, A-D-3003 \\ Architecture School, Tianjin University, No.92, Weijin Road, Nankai District, Tianjin,China \\ lioncats@qq.com, heyongjian@tju.edu.cn
}

\begin{abstract}
Keywords: Hua Ming Mode; Exchange the rural homestead for the house in town; Small town construction; Urbanization.
\end{abstract}

\begin{abstract}
The article summarizes the" Hua Ming Mode" of the small town construction in Tianjin. Namely "contract responsibility system remains untouched, arable land amount keeps unchanged, rural residential demand gets respected, and house and homestead can be exchanged". The success to the "Hua Ming Mode" is resolving contradictions of rural and urban land usage, and achieving the balance between "land" and "capital' in the project. However, it has its limitations; the mode requires a specific economic environment, and it must be in the suburbs near metropolitan and gets the land circulation index support. In the end of the article, suggestions are provided to the issues: "rural residents underemployment " and " material urbanization prior to ideology urbanization ".
\end{abstract}

Since 2005, in order to speed up the small towns construction in the city of Tianjin, promote rural urbanization and promote the overall development of the urban and rural areas, the government, combining the characteristics of the social and economic development in Tianjin, puts forward a new thinking for the small town construction, namely, "contract responsibility system remains untouched, arable land amount keeps unchanged, rural residential demand gets respected, and house and homestead can be exchanged". The core content is to make the link between the increasing urban construction land and the decreasing rural construction land. On the premise of guaranteeing the dynamic balance of the total arable land during the planning period, the government reinforces the rural residential renovation with the breakthrough point of exchange arable land with homestead, so as to revitalize the stock of rural land. In line with the principle of "pilot project with priority" and "development with successive steps", in the second half of 2005, Tianjin carried out the city's first batch of rural small towns construction pilot projects, Hua Ming Town in Dong Li district, Xiao Zhan Town in Jin Nan district and Da Liang Town in Wu Qing district, in Nan Beixin Village, in Hou Pubang Village, in total, involving 37 administrative villages, 66000 rural residents, and 2.91 million $\mathrm{m} 2$ of rural residential area, which is in the planning of small town construction. In the first batch of pilot experience, on the basis of the first half of 2007, the government approved 9 towns and 3 villages as the second batch of pilot projects, such as Zhang Jiawo Town in Xiqing District, Ba Litai Town in Jinnan District and Cha Ding Town in Han Gu District, Shuang Jie Town in Bei Chen District, involving 92 administrative villages, 111000 rural residents, 5.63 million $\mathrm{m} 2$ of rural residential area, which is in the planning of small town construction. By the end of 2008, more than 100000 rural residents have left their old houses, and moved in commodity houses with property rights.

Based on the "exchanging rural homestead for house in town", Hua Ming town is the first demonstration town that carries out the planning construction under the guidance of the new thinking. Centered on the construction practice of Hua Ming town, Tianjin government has selected specialized personnel from the relevant departments for this and has carried out small town construction system, supporting policies, operation modes and other 14 special subjects studies. Together they have formed a set of operable theories, policies and systems, which reveals innovation requirements, and the coordination of urban construction and development. It guides the rural urbanization moving forward and promotes the overall development of urban and rural areas. To this, 
this article will study the case, under the guidance of the small town construction mode - Hua Ming Mode.

\section{The core content of "Hua Ming Mode"}

The core content of Hua Ming Mode can be summarized as "exchanging rural homestead for house in town". First of all, on the premise of acquiring a certain land circulation index, the government establishes the planning of the small towns construction (including land consolidation planning). And the construction land index, after the evaluation, can be applied to get mortgage from the bank, and the capital will be used for the construction of resettlement residential area and infrastructure for rural residents in the small town. With voluntary premise, on the basis of a certain standard, rural residents can exchange their rural homestead for a house in town, and move into the town to live. Then, in accordance with the land consolidation planning, the government rehabilitates the original rural residents' homestead so as to return the earlier occupied land circulation index. Finally, the leftover construction land will be sold in the city real estate market by the approach of bid invitation, auction and listing so that the sales revenue can be used to repay the government loan, with the interest, to the bank. The implementation process of the mode is showed in figure 1.

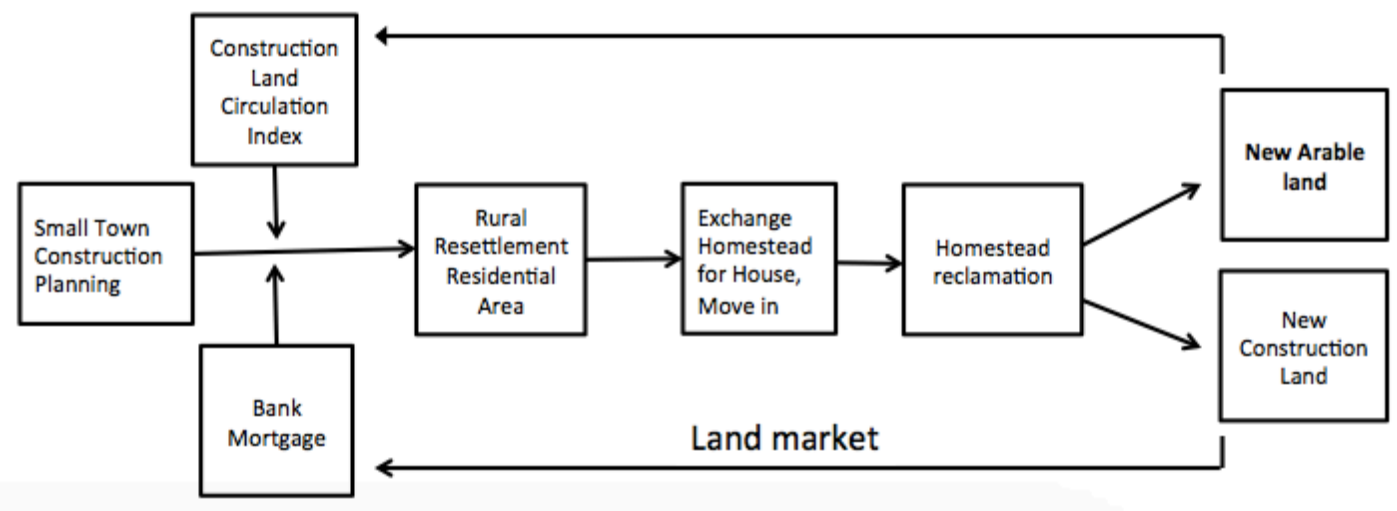

Figure 1:The implementation process of the mode.

Taking Hua Ming town as a case, the total rural construction land in town reaches 804 hectares, by establishing the planning of Hua Ming demonstration town, it is can be seen that the construction land index is concentrated in the township, 562 hectares, namely, on the north side of Jing Han road and on the both sides of Yang Bei road. The area overlaps 314 hectares of the arable land, which can be acquired by realizing the land circulation index. In the planning, 233 hectares land will be used for resettlement residential area and public facilities for rural residents, and its investment is about 3.7 billion RMB, which can be obtained by getting a mortgage from the bank. The patch of the residential buildings has been built in July, 2007, and more than 40000 rural residents have successively moved in; in addition, 329 hectares of the land will be used for commercial development. After sale, the revenue is expected to reach 4billion RMB. so far the government has built an ecological park, a residential area with the new immigrant property rights, a garden business area and other commercial real estates. Comparing with previous state, the total the rehabilitated arable land reaches 363 hectares, including the newly increased 49 hectares, which has achieved the objective of keep the balance between increasing urban construction land and decreasing the rural construction land. Meanwhile, the sale revenue of 329 hectares commercial development area can ensure the capital balance that government has invested in the construction of the resettlement residential area. This kind of "double balance" is an essential condition for later practice of other demonstration small town construction.

In the practice of the small town construction, in recent years Tianjin has showed the "exchanging rural homestead for house in town” strategic measure has a far-reaching significance. Firstly, It puts forward a new mode of accelerating the rural urbanization in developed area in our country, and 
creates a new way of the rural collective land reconsolidation, rural construction land circulation and Intensive utilization. Secondly, it focus on the construction of rural resettlement residential area, improves the living environment of the rural residents, and realizes the obtaining of the commercialization and property rights of the rural residential house, in order to substantially increase the property income and unearned income of rural residents. Thirdly, it opens up a new way of re-consolidation, circulation and intensive utilization of the rural construction land. It is an effective means of solving the urban land resource shortage and financial constraints of small town construction. It promotes the construction of the new socialist countryside and changes the dual structure in urban and rural economy, which has an important practical significance.

\section{The Successful Experience of Hua Ming Mode.}

\section{Respecting the demand of rural residents}

In 2005, the industrial structure of Hua Ming Town is 67:41.9:51.4. Agriculture has a rather low status in the township economy; the industrial sector here generally refers to the processing industry, including vehicle repairing, chemical engineering, hardware, machinery and food etc.; tourism and transportation industries are wel-developed. Seen from the employment structure, $90 \%$ of the rural residents no longer participate in the agricultural production; more rural residents are actually working for Tianjin Airport Processing district. The relatively high income not only provides the residents with financial security, but also urges them to change their living conditions. They no longer dependent solely on land and the ones with more average construction land are willing to trade their land use right in the market when facing the real estate developer's demand. In general, the rural residents in Hua Ming Town are willing to trade their collective construction land use right by exchanging their homestead for a house in city.

\section{Solve the prominent contradictions of the rural-urban land use}

The urbanization of Tianjin has gradually entered the stage of suburbanization since 2000. The function of urban residential overflowing has replaced the production function as the main driving force for the expansion of the central city. However, Hua Ming Town, located in the outskirts of the town center, actually has become an urban-function region. Because of the extension of living space in urban area and the construction of external traffic arteries, Hua Ming Town has become an urban function area with no town and no district. At the same time, Tianjin Binhai airport and airport logistics processing zone are within the scope of Hua Ming Town's domain, making the rural residents of Hua Ming Town, as a matter of fact, have become urban industrial workers. Meanwhile, the development of land within Hua Ming Town still has strong rural characteristics, where the land use is scattered and the structure is unreasonable. 15 scattered in the whole town 19 industrial enterprises in the village, the land for residential building accounts for $36.48 \%$ of all construction land in town, higher than the sum of the land for construction and warehouse production. The fundamental reasons for this phenomenon are that when urban and rural function are integrated, Hua Ming Town still retained the executive institution of town level, thus caused the urban and rural land use dually. The contradictions between urban and rural economic development and land supply have severely restricted the economic and social progress in urban area and Hua Ming Town. In this case, through the "exchanging rural homestead for house in tome", breaking down barriers of administrative system can solve the contradiction between land demand and supply when urban area is expanding and urban and rural function are integrating, which not only conforms to the rule of urbanization, but also is a great exploration of solving agriculture issues in Hua Ming town. 


\section{Achieving "land balance” and "capital balance” of land exploitation in advance}

In order to implement the "Hua Ming Mode", there are two prerequisites, i.e. "land balance" and "capital balance”. When Tianjin conducted pilot projects on small town construction in 2005, the two balances have already been achieved. At that time, Hua Ming Town has 12 villages, consisting of 13268 households and a population of 41063. The construction land covers an area of 805 hectares with an average area of 0.06 hectares $(0.9 \mathrm{mu})$ of each household. The average household construction land area has all reached 333 square meters $(0.5 \mathrm{mu})$. The experience of the construction of small cities and towns in Jiangsu Province and Zhejiang Province shows that, when the average household construction land area exceeds $0.5 \mathrm{mu}$, the "land balance", one of the prerequisites of rural residents realizing “exchange of homestead for house in city”, can be achieved.

Meanwhile, two factors have promoted the rapid development of the real estate market of Tianjin in 2005: one was the exploitation and opening of Tianjin Binhai New Areas, which has pushed the population of other provinces around the area to aggregate in Tianjin. These people have strong demand for purchasing houses and they would often choose cheaper houses in the near suburb; the other factor was the large-scale renovation of the old city districts and the construction of new city districts in 2003, aiming to solve the old issue of living environment. The two factors have together promoted the rapid expansion of the living space in the central urban district to the near suburb outside the outer-ring road. In addition, this kind of expansion was mainly led by real estate proprietors, which offered "capital balance" for building houses for the rural residents. First solving the housing problem of rural residents, then recollecting the cost by real estate development, and finally developing industries to provide job opportunities for the rural residents move in. This explains why the "Hua Ming Mode" is reasonable and practical.

\section{Limitations of the "Hua Ming Mode"}

The "Hua Ming Mode " illustrates the philosophy of small town development in Tianjin, which may offer valuable experience in other similar cases in Tianjin and other provinces. However, the practice of "exchanging rural homestead for house in town" of Hua Ming in 2005 in Tianjin had its particularity. From the five-year experience of the three pilot projects of small town construction, this mode has its own limitations.

\section{Requiring stable economic environment in a macro-economic sense}

The three years after the pilot project of Hua Ming Town was a time when the world economy boomed and China's economic development was at its high time. People held a positive attitude towards the economic development, which in turn increased the urban housing prices, which had already been unreasonable. This is especially true in the developed coastal cities and the first-tier cities like Beijing, Tianjin, Shanghai and Shenzhen. Against this macro-economic background, the land fiscal revenue the government had earned from the land market could sufficiently compensate the previous investment on building houses for the rural residence. Therefore, only when the government can maintain "capital balance", can the "Hua Ming Mode" be realized. However, the financial crisis broke out in America in 2008 has dragged the world economy into its downturn and China was no exceptional. The shrink of the overseas market demands directly reduced the export and import volume, affecting China's national economic development. The real purchasing power of people has been weakened and the majority was holding money and waiting to see the ups and downs of the housing price. Because of this, the planning of the third pilot project of small town construction since July 2008 has encountered the "capital balance” problem.

In order to reverse the negative impact of world financial crisis on China, China has issued economic policies and monetary policies for stimulating the domestic demand. These policies have achieved significant effects, helping industrial production to recover and employment rate to turn from its downturn gradually; however, they also have some "side-effects", like the increase of inflation and the real estate bubble etc. In order to solve these problems, China has issued a series of 
regulatory policies targeting the real estate market, which has achieved some effects within a short period of time. However, this has resulted in obvious "fluctuation" of the housing price in the near suburb of Tianjin in the past five years and has exerted unfavorable Influence on the small town construction: the "capital balance" has, intermittently, become "capital unbalance". Seen from this, it is clear that "Hua Ming Mode" requires relatively stable macro-economic environment.

\section{Only applicable to near suburb in a Meso-economics sense}

First, the function of the small town in near suburb tends to be integrated with that of central urban district and this is the economic basis of "Hua Ming Mode" to implement the small town construction in the near suburb. The urbanization process of the developed countries shows that after the preliminary stage with aggregation as its main feature, suburbanization (i.e. an off-center phenomenon where people and industrial enterprises move away from the city center) has emerged due to reasons like high rent, crowded traffic and dissatisfying living environment in city centers. Under the influence of diffusion mechanism of space factor, the relocation of the population and industries will often be arranged along the traffic line to the outside. They choose to continue to develop in the near suburb of the big city, making the small towns in the suburb to become the functional groups of the central district. Comparatively speaking, the small towns in the outer suburb are less influenced by the city central district and have less necessary economic connection with it; it is still in the "growing point of professionalization", therefore, according to the general principle of urbanization, "Hua Ming Mode" is more suitable for the small town construction in the near suburb rather than in the outer suburb. Second, the employment structure, lifestyle and cultural mindset etc. of small town residence in the near suburb are closer to that of people live in the central district, which means it is easier for them to fit in the urban social groups and this is the mass base of the application of "Hua Ming Mode" to the small town construction in the near suburb. For example, the "rural residents" in Hua Ming Town have already changed to work in modern industries or service industries like transportation, catering etc. They have abandoned their dependence on land since they no longer work in agricultural industry. According to a survey, the majority of rural residents yearn for city life; thus, they are willing to change their homestead for a house in the city. On the contrary, in the second and third pilot projects of small town construction in Tianjin, the rural residents in the outer suburb are highly independent on land and agriculture in terms of economy and employment; therefore, "Hua Ming Mode" lacks mass base in the small town construction in outer suburb. Comprehensively speaking, "Hua Ming Mode" is only applicable to small towns in the near suburb which is situated in the major axis of urban space development. The closer the distance between the small town and the urbanization area, the more applicable the implementation of "Hua Ming Mode" will be.

\section{Requiring land circulation index support in a Microeconomics sense}

"Hua Ming Mode" must be implemented on the premise of requisition-compensation balance of arable land; it requires the small town, which implements the planning of the "Exchanging rural homestead for house in tome", acquiring a certain land circulation index. However, with the amount of total arable land in China reaching a boundary line 1.8 billion mu, getting a land circulation index becomes more and more difficult. in order to avoid the situation as blindness enclosure movement and attach more importance to construction instead of reclamation, in 2008, Ministry of Land and Resources issued "experimental regulation to increase or decrease construction land in urban and rural area " it requires to select pilot units, to draw up an implementary plan and to ensure the scale, the scoop and the layout of the increasing construction land in urban area and merging construction land in rural area.

Major issues and suggestions in the implementation 


\section{Major issues}

\section{Underemployment of landless rural residents}

Before the Hua Ming town is constructed, a series of researches have made on this topic and a set of special planning has been conducted. In order to guarantee the employment and the life of landless residents, besides "land balance" and "capital balance" policy, the government has also formulated a series of supporting policies, such as Medicare, social subsistence allowances and pension. If the planning intends to have a relatively concentrated commercial business district located in Hua Ming town, it can provide about eleven thousand jobs. Plus the employment population in Tianjin Airport Processing district, the district basically can meet the employment needs of relocated rural residents. Meanwhile, in order to make rural residents adapt the requirements of the new work as soon as possible, the employment training class and rural resident school are also configured in the small town, the training is based on the demand of the jobs, for helping them to fit in the urban life as fast as they can. Unfortunately, a series of "work in contentment" policies goes off the track in process of implementation: up to $62 \%$ of the rural residents think the government has no job placement policies or they are completely unclear about government resettlement policy. In general, the satisfaction percentage of rural residents' to the "exchanging rural homestead for house in tome" policy is no more than $38 \%$. The government propaganda work and the change of the macro economic environment should be main reasons for the issue.

\section{“Material urbanization” is prior to “ideology urbanization ".}

"Hua Ming Mode“ essentially belongs to an approach that transforms the agriculture region into the urban region. Urbanization is not only a geographic concentration process of non-agricultural population and non-agricultural activities in urban region, but also a geographical diffusion process of city value and urban lifestyle in rural region. As "a urbanized subject", in 2 to 3 years, the landless rural residents can complete the living model transformation, from dispersion to concentration, from the agricultural to the non-agricultural. But it isn't easy to make the change on the thinking pattern that deeply rooted in agricultural production activity. Therefore, there will remain $70 \%$ landless rural residents that require engaging in planting and breeding industry. The reasons to the result are plenty, but the main one should be that as "Hua Ming Mode" emphasizing the "capital balance "and" land balance ", the insufficient attention is paid to the change of the rural residents ideology, which results in the material urbanization is prior to the ideology urbanization.

\section{The direction of the adjustment}

For the main problems occurred in the implementation, the direction of the adjustment can points to the following two aspects.

\section{Taking the "employment balance" as one of the premises of the "Hua Ming Mode" implementation.}

On the basis of keeping the "double balance", we should also take employment placement of landless rural residents into planning balance system, and extend the "double balance" to the "triple balance". Since the market is unstable, the realization of the employment balance is difficult to achieve the "double balance". So that it requires several of employment safeguard measures during the establishment of the planning. The government except guides the landless rural residents to traditional secondary and tertiary industries, it should also guide them to participate the adjustment of agricultural structure. Since the suburb small town can develop new mode of agricultural industry, such as urban agriculture, ecological agriculture, etc. it is able to promote re-employment of the rural mature-stage residents. 


\section{Strengthening propaganda work of changing the thinking pattern of landless rural residents.}

Firstly, establishing different cultural facilities. Besides employment training class and rural resident school for the landless rural residents, other social public service facilities, which are similar to the ones in urban communities, such as: community library, the elderly activity room should be configured. Secondly, intensifying organizational study for the landless rural residents. By propagandizing urban culture and citizen code, government can gradually change the deep-rooted traditional values and living habits of the landless rural residents. Thirdly, establishing a set of cultural learning system. For the rural residents to learn labor skills and urban culture, the government should establish a complete learning and communication system, that is to say, establish a location, time, and trainer " three-element fixed" learning system.

\section{Conclusion}

"Hua Ming Mode" as an active exploration, by adopting "exchanging rural homestead for house in tome” as a major approach in Tianjin, it solves the land and capital problems during the sub-urbanization process. Experience has approved that the small town construction mode can bring positive effects on consolidating the urban and rural land, improving rural area environment and shortening the distance between urban and rural area. At the mean time, it solves problems of rural residents employment placement and their thinking pattern transformation. As long as we take positive countermeasures, it is an inevitable fact to any new emerging things; "Hua Ming Mode" has the guiding significance for the urban-rural development.

\section{References}

[1] Huang Jingtao, Fu Fangsheng. Tianjin Huaming demonstration town City planning and design [J], 2009 (6): 3- 8

[2] Yang Xingquan. The urban and rural economic development and intensive use of rural and urban fringe [J]. (12): 49 - 2007

[3] Yuan Qingmin, Xue Xiaoyan. The integration of urban and rural land intensive use of Tianjin Huaming town mode [J]. Journal of Jiangxi Agricultural University (SOCIAL SCIENCE EDITION), 2009 (2): 5 - 7

[4] He Yongjian, Li Nan, Dong Xiaoyu. Since 1990, Tianjin downtown residential spatial structure evolution [J]. Urban problems, 2006 (6): 65 - 69

[5] Hua Liping. Analysis of rural residential land problems and mitigation plan [J]. Zhejiang land resources, 2005 (4): 39 - 38

[6] Hu Zhaoliang. The financial crisis and the growth of [J]. Chinese financial center city, 2008 (12): 3- 6

[7] Gu Chaolin, Zhen Feng, Zhang Jingxiang. Agglomeration and diffusion -- new theory on urban space structure [M]. Nanjing: Southeast University Press, 2001: 138 - 139

[8] Hu Yunxia. Rural Homestead wards transfer performance study [J]. The construction of small towns, 2008 (4): 77- 81 